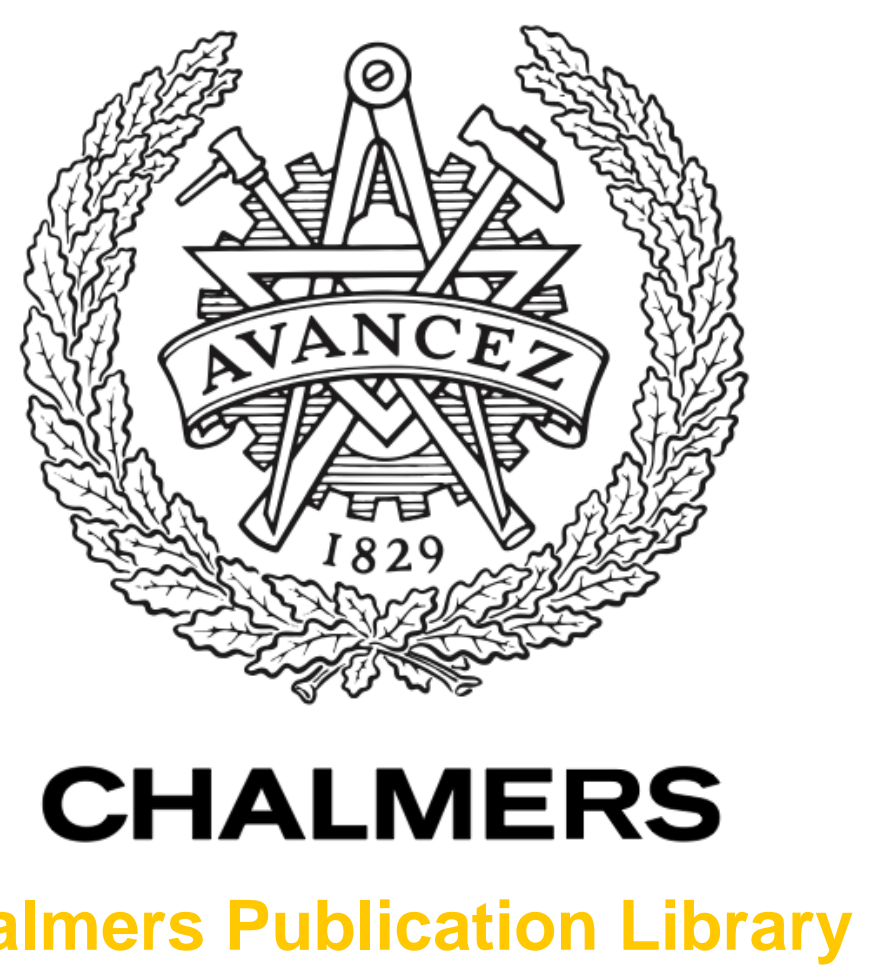

Challmers Publication Library

\title{
Coastal Sea Level Measurements Using a Single Geodetic GPS Receiver
}

This document has been downloaded from Chalmers Publication Library (CPL). It is the author's version of a work that was accepted for publication in:

Advances in Space Research (ISSN: 0273-1177)

Citation for the published paper:

Larson, K. ; Löfgren, J. ; Haas, R. (2013) "Coastal Sea Level Measurements Using a Single Geodetic GPS Receiver". Advances in Space Research, vol. 51(8), pp. 1301-1310.

http://dx.doi.org/10.1016/j.asr.2012.04.017

Downloaded from: http://publications.lib.chalmers.se/publication/157242

Notice: Changes introduced as a result of publishing processes such as copy-editing and formatting may not be reflected in this document. For a definitive version of this work, please refer to the published source. Please note that access to the published version might require a subscription.

Chalmers Publication Library (CPL) offers the possibility of retrieving research publications produced at Chalmers University of Technology. It covers all types of publications: articles, dissertations, licentiate theses, masters theses, conference papers, reports etc. Since 2006 it is the official tool for Chalmers official publication statistics. To ensure that Chalmers research results are disseminated as widely as possible, an Open Access Policy has been adopted.

The CPL service is administrated and maintained by Chalmers Library. 


\title{
Coastal Sea Level Measurements Using a Single Geodetic GPS Receiver
}

\author{
Kristine M. Larson \\ Department of Aerospace Engineering Sciences, University of Colorado \\ Boulder, CO USA \\ Johan S. Löfgren and Rüdiger Haas \\ Department of Earth and Space Sciences, Chalmers University of Technology \\ Gothenburg, Sweden
}

\begin{abstract}
This paper presents a method to derive local sea level variations using data from a single geodetic-quality Global Navigation Satellite System (GNSS) receiver using GPS (Global Positioning System) signals. This method is based on multipath theory for specular reflections and the use of Signal-to-Noise Ratio (SNR) data. The technique could be valuable for altimeter calibration and validation. Data from two test sites, a dedicated GPS tide gauge at the Onsala Space Observatory (OSO) in Sweden and the Friday Harbor GPS site of the EarthScope Plate Boundary Observatory (PBO) in USA, are analyzed. The sea level results are compared to independently observed sea level data from nearby and in situ tide gauges. For OSO, the Root-Mean-Square (RMS) agreement is better than $\mathbf{5} \mathbf{~ c m}$, while it is on the order of $10 \mathrm{~cm}$ for Friday Harbor. The correlation coefficients are better than 0.97 for both sites. For OSO, the SNR-based results are also compared with results from a geodetic analysis of GPS data of a two receivers/antennae tide gauge installation. The SNRbased analysis results in a slightly worse RMS agreement with respect to the independent tide gauge data than the geodetic analysis $(4.8 \mathrm{~cm}$ and $4.0 \mathrm{~cm}$, respectively). However, it provides results even for rough sea surface conditions when the two receivers/antennae installation no longer records the necessary data for a geodetic analysis.
\end{abstract}

\section{Introduction}

Rising global mean sea level has the potential for significant impact on coastal societies. Thus it is of great importance to monitor and understand how local sea level is changing (Bindoff et al., 2007). Sea-level measurements have traditionally been made with coastal tide gauges. During the past two decades, a series of very precise satellite altimetry missions have been launched, allowing large-scale measurements of sea-level motion. In order to use altimeter data to compute mean sea level variations over time, there is a need to account for bias and drifts in the altimeter, as these effects can be of the same order of magnitude as the sea level signal itself. Studies have shown that altimeter bias and drifts can be corrected in a robust way if a global distribution of tide gauges is available (Chambers et al., 1998; Mitchum, 1994; 2000).

The technology for measuring sea level at a coastal site is well established via tide gauges (IOC, 2006). However, even an accurate tide gauge measures not only sea level but also the motion of the ground. Thus, effects such as glacial isostatic adjustment, coseismic and postseismic deformation, and land subsidence make it difficult to use tide gauges either to measure sea level directly or to calibrate altimeters. It is relatively straightforward to use Global Positioning System (GPS) receivers to measure these so-called local "land effects," however efforts to do so 
have been hampered by the lack of GPS receivers near tide gauges and the absence of all needed GPS positioning solutions in a common reference frame (Schöne et al., 2009). Löfgren et al. (2011a) suggested that a GPS tide gauge could be used to determine both local ground motion and sea level. Using standard geodetic off-the-shelf equipment, the GPS tide gauge developed by Löfgren et al. is comprised of two receivers and antennae. They successfully demonstrated its ability to measure local sea level over a 3-month period. In the present paper, the concept of a GPS tide gauge is revisited, asking the question as to whether a single GPS receiver/antenna system could also serve as a GPS tide gauge.

\section{GPS Tide Gauges}

The concept of using reflected GPS signals for environmental sensing was first introduced by Martin-Neira (1993). This initial paper and others have focused on altimetry, i.e. observing GPS reflections from the ocean surface on a spaceborne platform (Lowe et al., 2002; Cardellach et al., 2004). Much of the land-based work done to observe water reflections has been done with the goal of validating a potential GPS-based altimetry mission. Although there are exceptions (see e.g. Treuhaft et al., 2001 and Rius et al., in press), the traditional GPS tide gauge consists of two GPS antennae (Figure 1, top). The zenith-pointing antenna is designed to receive the direct signal, and is thus Right-Handed Circularly Polarized (RHCP), the same as the transmitted signal. The nadir-pointing antenna is optimized to receive the reflected signal, which becomes primarily Left-Handed Circularly Polarized (LHCP) after reflection. The grazing angle of the reflected signal corresponds to the elevation of the direct signal (see Figure 1). The proportions of RHCP and LHCP energy depend on the dielectric constant and the conductivity of the reflecting surface and the satellite elevation angle. For seawater, the LHCP component dominates the reflection for elevations above $\sim 8^{\circ}$, whereas the RHCP component decreases rapidly (see discussion in Hannah, 2001). For the two antennae GPS tide gauge, one can estimate the sea level by comparing the direct and reflected signals. Assuming the phase centers of the two antennae are offset by an amount $d$, the path delay of the reflected signal relative to the direct signal can be determined by simple geometry. The height $h$ of the water surface is defined as:

$$
\mathrm{h}=0.5^{*}(\Delta \mathrm{v}-\mathrm{d})
$$

where $\Delta v$ is the estimated height difference for the baseline between the two antennae (Belmonte-Rivas and Martin-Neira, 2006). Because it is a very short baseline, simple GPS analysis software can be used to estimate h (Löfgren et al., 2011a; 2011b). Various methods have been used to extract sea level heights from the raw GPS observations, e.g., using interferometric techniques with code and phase measurements, customized receivers, and geodetic techniques with standard off-the-shelf receivers (Martin-Neira et al., 2001; Cardellach et al., 2004; Belmonte-Rivas and Martin-Neira, 2006; Dunne et al., 2005; Soulat et al., 2004; Löfgren et al., 2011a; 2011b). In each of these previous GPS tide gauge studies, the investigators have designed their experimental equipment (specifically the LHCP antenna) with the objective of observing reflected signals. However, this does not mean that the RHCP antenna is not also sensitive to sea surface reflections. Although the purpose of the zenith-directed RHCP antenna is to maximize the direct signal and suppress reflected signals, it is well known that it does not completely reject energy from reflected signals. Methods to correct for these reflections (known as multipath) in 
the GPS literature extends from the late 1980s to the present (Georgiadou and Kleusberg, 1988; Elosegui et al., 1995; Jaldehag et al., 1996; Hannah, 2001; Park et al., 2004; Bilich et al., 2008).

Most of these efforts focus on the assumption that multipath is repeatable and can be modeled as a specular reflection. Recently, characteristics of these multipath ground reflections have been used to sense soil moisture and snow depth (Larson et al., 2008; 2009). For these applications, the distance of the reflecting, planar surface (h) from the RHCP antenna phase center is determined from the interference pattern caused by the direct and reflected signals. These multipath interference patterns can be observed in the pseudorange, carrier phase, and Signal-toNoise Ratio (SNR) data. For SNR, the effect becomes clearly visible when showing the SNR as a function of elevation angle. Multipath oscillations in SNR (here designated $\delta S N R$ ) data can be expressed as:

$$
\delta S N R=A \cos \left(\frac{4 \pi h}{\lambda} \sin (\theta)+\phi\right)
$$

where $\lambda$ is the GPS carrier wavelength, $\mathrm{A}$ is the amplitude, $\theta$ is the satellite elevation angle, and $\phi$ is a phase offset. For horizontal planar reflectors, the multipath modulation frequency is constant $(2 * \mathrm{~h} / \lambda)$ for sine of the satellite elevation angle. Benton and Mitchell (2011) used a similar approach to examine sea surface reflections with SNR data. They found reflection frequencies that agreed to first order with expected values. In this paper the SNR data from geodetic-quality GPS receivers and antennas will be examined for three months to estimate local sea level. Examples from two geodetic-quality receivers will be shown.

\section{Experimental Results}

This study utilizes SNR observations on both the L1 and L2 frequencies (S1 and S2) from geodetic-quality zenith-pointing antennae at the Onsala Space Observatory (OSO) and Friday Harbor. S1/S2 are referred to as signal strength in the RINEX specifications (Gurtner, 1994). Standardized RINEX S1/S2 would correspond to the quantity called carrier-to-noise-density ratio $(\mathrm{C} / \mathrm{N} 0)$, the ratio of signal power to the noise power spectral density. SNR is related to C/N0 through the noise bandwidth (B) as in SNR $=(\mathrm{C} / \mathrm{N} 0) / \mathrm{B}$ (Joseph, 2010), thus having units of decibels (in logarithmic scale) or watt per watt (in linear scale - sometimes in volt per volt when taking the square root). For simplicity, S1/S2 observations will be reported as SNR, assuming a 1 $\mathrm{Hz}$ bandwidth and volts when converted to a linear scale.

\subsection{Onsala, Sweden}

The OSO GPS tide gauge site used in this study was previously described by Löfgren et al. (2011a; 2011b). For the sake of completeness, the key points are summarized here. The site was installed as a traditional GPS tide gauge at OSO, south of Gothenburg, Sweden. It consists of two dual-frequency geodetic-quality carrier-phase GPS receivers of type Leica GRX1200 operating at 1 sample/sec. The zenith-pointing antenna is a standard geodetic-quality choke-ring model: Leica AR25. The nadir-pointing antenna is a specially-designed LHCP choke-ring Leica AR25, i.e., an AR25 choke-ring antenna body with a LHCP antenna element. Unlike some of the other GPS tide gauge studies previously mentioned, the Onsala installation uses geodetic-quality receivers with commercial tracking loops. In other words, the receivers have not been optimized to track reflected signals, which are not as strong as direct signals. 
The antennae were mounted on the same vertical axis on a wooden boom that was attached to a small wharf, approximately $1.5 \mathrm{~m}$ above the mean sea level. Unlike a ground-mounted GPS site, the Onsala antennae were installed directly above the sea surface (Figure 2). As previously described by Löfgren et al. (2011a; 2011b), the size and shape of the sensing zone of GPS reflections varies as a function of elevation angle and the antenna height above the sea surface. Low elevation signals reflect farthest away and with the largest reflection zone. For a typical antenna height of $1.5 \mathrm{~m}$, the size of the reflection zone varies from $2 \mathrm{~m}^{2}$ to $7 \mathrm{~m}^{2}$ for elevation angles of $15^{\circ}-40^{\circ}$. Visual inspection was used to establish which azimuth range from the installation provided unobstructed views of the sea surface. This resulted in azimuth angles between $100^{\circ}$ and $200^{\circ}$. While GPS tide gauges in public harbors would be hampered by reflections off boats and other manmade objects, OSO is an area with restricted access that does not have any boat traffic.

Given that almost all GPS applications use the carrier phase and/or pseudorange data, typical behavior of SNR data is not as well known by the users of geodetic-quality GPS instruments. For a geodetic-quality GPS antenna, such as the choke rings used in this study, signal power levels rise as the satellite rises from near the horizon ( 5 degrees) to zenith, shown for the Onsala GPS tide gauge in Figure 3. In this example, the L1 SNR data (S1) are shown varying from $\sim 45$ to 53 $\mathrm{dB}$. These values are consistent with a receiver using code-based tracking (Larson et al., 2010). The S2 data for this receiver have much lower power levels and were not used. Because the direct signal is dominant, it is difficult to see the impact of sea surface reflections in Figure 3. Figure 4 shows the previously-described SNR data with a $2^{\text {nd }}$ order polynomial removed. The polynomial is representative of the direct signal, and is not of interest for measuring sea level variations. The remainder SNR signal shown in Figure 4 is caused by ocean reflections. For a choke-ring antenna and a planar horizontal surface, the oscillations shown in Figure 4 should be of constant frequency as a function of sine of elevation angle (see Equation 2). Note however the large noise values at elevation angles below $20^{\circ}$ (corresponding to a value of 0.34 in Figure 4). This suggests that either the sea surface is not very planar over the reflective surface, or there are reflections from both the sea surface and small islands across the inlet. Because the low elevation data do not agree with the model for water reflections, at this site only data between $18^{\circ}$ and $40^{\circ}$ will be used to estimate the multipath frequency. This elevation angle spans 45-65 minutes, depending on which track is being used. This long time span represents a significant restriction of the SNR-based reflection method for sea level measurements. For regions with large coastal sea level variations, as will be seen for the second example, the assumption of a single reflection frequency over the satellite track will break down. At the OSO site, sea level generally does not change very quickly.

As for recent snow studies (Larson et al., 2009; Larson and Nievinski, 2012), the dominant multipath frequency in the SNR data was estimated using the Lomb Scargle Periodogram (LSP) (Press et al., 1996). One advantage of the LSP over traditional Fourier techniques is that the observations do not have to be evenly sampled. (The OSO data are evenly sampled in time, but not as a function of sine of the elevation angle). Furthermore, it is straightforward to specify oversampling factors that provide LSP output at the frequencies of interest (the longer periods) rather than the short periods. In this study an oversampling factor of 40 was used; this corresponds in terms of reflector height h retrieval precision to $\sim 3 \mathrm{~mm}$. Figure 5 shows the LSP for the three satellites shown in Figure 4. Although there is clearly a dominant peak in each time 
series, it is notable that these reflections are much weaker than observed in similar studies devoted to snow retrievals from SNR data (Larson and Nievinski, 2012). There are also significant differences in the strength of the retrievals. In order to automate the sea level retrievals, it was deemed successful if the magnitude of the LSP peak was 2.5 times that of the average LSP noise.

\subsection{Onsala GPS Tide Gauge Results}

GPS data from Onsala for 2010 (September 16 through December 16) were analyzed. The closest tide gauge records from the Swedish Meteorological and Hydrological Institute (SMHI) are at Ringhals (18 km south) and Gothenburg (33 km north). For comparison, a synthetic tide gauge record was computed $(0.4 *$ Gothenburg and $0.6 *$ Ringhals) to approximate the sea level record for Onsala. The ratios used to compute the synthetic tide gauge were based on the distance of the tide gauges from Onsala. For each satellite, a bias was estimated for the threemonth period by minimizing the residual between the GPS sea level heights and the synthetic tide gauge record. This bias reflects the distance from the GPS phase center to mean sea level as defined by the SMHI. A total of 24 satellite tracks are visible each day at OSO for the azimuth range used. The GPS and synthetic tide gauge records are shown in Figure 6. The GPS results clearly follow the general signature of the tidal variations over the three-month period. There is no apparent drift in the GPS tide gauge records. The standard deviation of the residual between the GPS tide gauge and the synthetic tide gauge is $4.8 \mathrm{~cm}$. The correlation between the synthetic tide gauge and the GPS tide gauge is shown in Figure 7; the correlation coefficient is 0.97.

\subsection{Friday Harbor, WA}

The Friday Harbor GPS tide gauge (Figure 8) is located $\sim 130 \mathrm{~km}$ northwest of Seattle, Washington (U.S.). Unlike OSO, the Friday Harbor site was never meant to be used to measure ocean reflections. Friday Harbor was installed for tectonic studies, one of the 1100 GPS receivers that make up the EarthScope Plate Boundary Observatory (PBO) (http://www.earthscope.org). The receiver is a Trimble NetRS; the antenna is a Trimble choke-ring with a radome. The receiver operates at 1 sample every 15 seconds. Unlike the Leica receiver, where all satellites in a specific azimuth mask were used, the analysis of the Friday Harbor data has been restricted to L2C transmitting satellites. Previous studies have shown that the L2C SNR data from the Trimble NetRS are of very high quality (Larson et al., 2010). Unfortunately, this means that for this site, fewer satellite tracks (5) are available for monitoring sea level than at OSO. However, the dataset is more than sufficient to demonstrate that GPS reflections can be observed at this site and that they are consistent with tidal variations.

Whereas the OSO GPS antenna was deliberately set above the sea surface, Friday Harbor's monument is drilled into bedrock many meters from the ocean. Many azimuth angles are blocked by nearby mountains and buildings (see Figure 8). Local sea level can be observed to the east and south of the monument; lower elevation angles rather than higher elevation angles must be used at this site to avoid reflections from the soil and rocks near the antenna. Therefore, the elevation range used for this site is $5^{\circ}-15^{\circ}$. Unlike the OSO data, where satellite tracks commonly took one hour, for these elevation angles a satellite track is $\sim 25$ minutes.

While the GPS dataset at Friday Harbor is smaller and more restricted than at OSO, the results from GPS reflections at this site can be compared with results from a National Oceanic and 
Atmospheric Administration (NOAA) tide gauge that is only 300 meters away. Furthermore, whereas daily tidal variations at Onsala are quite small $(\sim 20 \mathrm{~cm})$, at Friday Harbor peak-to-peak tidal sea level variations are $\sim 3 \mathrm{~m}$. Corresponding changes of reflection height $\mathrm{h}$ are $4-7 \mathrm{~m}$, and thus more cycles are visible in the SNR data than at OSO (see Figure 9). The red track, the GPS satellite with Pseudo-Random Noise (PRN) code 17, corresponds to a reflector height of $\sim 4 \mathrm{~m}$ and the green track (setting satellite with PRN 31) corresponds to $\sim 7 \mathrm{~m}$. Recall, these $\mathrm{h}$ values are the distance between the antenna and the sea surface, so that a smaller $h$ value means the sea surface is higher. From Equation 2, larger values of $\mathrm{h}$ mean that the multipath frequencies are higher, which is consistent with what is observed. The LSP results for these four GPS tracks are shown in Figure 10. Note that these amplitudes of the LSP periodograms are nearly twice as large as at OSO.

\subsection{Friday Harbor Tide Gauge Results}

GPS data from Friday Harbor for 2011 (July 5 through October 23) were analyzed. For each satellite, a bias was estimated for this three-month period by minimizing the residual between the GPS sea level heights and the NOAA tide gauge data. This bias represents the location of the phase center of the antenna with respect to the tide gauge datum. Because the tidal variations are so large, a 16-day subset of the GPS results is shown in Figure 11 to clearly illustrate the sea level variations. Although the GPS tide gauge convincingly records the overall behavior of the NOAA tide gauge (Figure 12, correlation of 0.98), the standard deviation of the residual between GPS and the in situ tide gauge is $\sim 10 \mathrm{~cm}$. This is much larger than was observed for Onsala. This is due to limitations in the simple model that was used to estimate the reflector height. Tidal variations at Friday Harbor are on average $20 \mathrm{~cm} /$ hour. Each satellite pass shown in Figure 9 takes $~ 25$ minutes, and thus the assumption of a horizontal planar reflector is inadequate. A better model would require estimation of a reflector frequency and frequency rate; this will be the topic of future work.

\section{Discussion}

What are the advantages and disadvantages of the two kinds of GPS tide gauges? The dataset of Löfgren et al. (2011b) overlaps with the one used in this study. Again using a synthetic tide gauge record to simulate sea level variations at Onsala, we can assess the precision of the two methods. Over the three months of the study, the standard deviation of the residual between the synthetic tide gauge and the GPS tide gauge results is $4.0 \mathrm{~cm}$ for Löfgren et al. (2011b) if three standard deviation residuals are removed. The RMS is $4.8 \mathrm{~cm}$ for the SNR-analysis presented here. We cannot assess the accuracy of either method because both studies eliminated a bias between GPS and the tide gauge record empirically. The SNR-based sea level retrieval presented here provides a temporal resolution that is determined by the number of satellite arcs, i.e., one sea level retrieval per satellite arc. On the other hand, the traditional GPS tide gauge analysis (using two GPS antennae) allows a much higher temporal resolution (Löfgren et al., 2010).

One advantage of using SNR analysis instead of traditional GPS tide gauge analysis is the superior performance during windy conditions. As shown in Figure 5 of Löfgren et al. (2011b), the nadir-pointing antenna/receiver system has difficulty tracking the reflected signal when the sea surface is rough, corresponding to wind speeds greater than $9 \mathrm{~m} / \mathrm{s}$. There was little indication of wind speed correlation in the SNR-study presented here, because the receiver was tracking the direct signal, which is not impacted by wind. Figure 13 shows a one-week period of results for 
both studies, i.e., from the geodetic analysis of the GPS tide gauge and the SNR analysis. During the first five days, both systems show excellent sea level retrievals. The nadir-pointing receiver/antenna system then shows very poor tracking for almost two days, which correlates with very windy conditions.

Although of less importance, SNR data do not have cycle slips, whereas a geodetic-quality GPS receiver will be impacted by cycle slips, particularly when it is trying to track the lower power reflected signals. Since the baseline being determined is extremely small, fixing these cycle slips is not a significant limitation. Of greater importance, the single receiver/antenna system is half the cost of the traditional two receiver/antenna GPS tide gauge. No part of the receiver or antenna had to be specially designed or built. These GPS receivers operate with the same tracking loops used by surveyors and geophysicists.

\section{Conclusions}

The SNR-analysis of three months of GPS data collected using geodetic-quality receivers and antennae has demonstrated that such systems are capable of determining sea level with a precision of $\sim 5 \mathrm{~cm}$. This is a degraded performance relative to the geodetic analysis of the twoantenna/receiver GPS tide gauge system (Löfgren et al., 2011a; 2011b). The primary advantage of any GPS tide gauge is that it allows simultaneous determination of sea level and position with respect to the International Terrestrial Reference Frame system (e.g. as provided by its latest realization ITRF2008, Altamimi et al., 2011), in this study even using a single instrument. This is particularly useful in areas with land surface motion where the usefulness of traditional tide gauges is restricted. Because of its simplicity, the cost of the GPS tide gauge described here is half the price of the two-antenna/receiver GPS tide gauge system. It also has better performance in high wind conditions, but provides significantly worse temporal resolution than the twoantenna/receiver system in calm sea surface conditions (30-60 minutes vs. 5-10 minutes). Although the number of GPS sites very near the coast is small, as long as the SNR data are of high quality (Larson et al., 2010), these sites could be used as tide gauges. It would be interesting to examine existing GPS coastal sites to determine if long records could be extracted of both ground motion and sea level.

Even though GPS tide gauges are unlikely to replace traditional tide gauges, they might become extremely useful as a campaign instrument for researchers having an interest in monitoring water levels, even in tectonically active regions. For example, they could be used in altimeter validation/calibration experiments. Because they do not need to be located in the water, they are simple to install and operate and can be easily moved. For "deliberate" measurements of water reflections using a geodetic-quality GPS instrument, the antenna could be turned to the horizon, thus increasing the strength of the reflected signals. Extending this concept to use satellite signals of other GNSS will improve the temporal resolution of the geodetic tide gauge and allow a more comprehensive comparison.

\section{Acknowledgements}

K.L.'s work was supported by a $150^{\text {th }}$ Anniversary Visiting Professorship at the Chalmers University of Technology. The U.S. National Science Foundation (NSF) supports reflections research at the University of Colorado: EAR 0948957 and AGS 0935725. Some of the material in this paper is based on data, equipment, and engineering services provided by the Plate 
Boundary Observatory operated by UNAVCO for EarthScope (http://www.earthscope.org) and supported by the NSF (EAR-0350028 and EAR-0732947). The GPS data from Friday Harbor shown in this paper are freely available from UNAVCO. The NOAA tide gauge data (Station 9449880) were downloaded from http://tidesandcurrents.noaa.gov. The Adlerbert Research Foundation partially funded the GPS tide gauge project at the Onsala Space Observatory. The receivers and antennae were purchased through the Leica Geosystems ATHENA program. The stilling well tide gauge data from Ringhals and Gothenburg were provided by the Swedish Meteorological and Hydrological Institute.

\section{References}

Altamimi, Z., Collilieux, X., Metivier, L., ITRF2008, An improved solution of the International Terrestrial Reference Frame, J. Geod., 85(8), 457-473, 2011.

Belmonte Rivas, M., Martin-Neira, M. Coherent GPS reflections from the sea surface, IEEE Geosci. Rem. Sens. Lett. 3, 28-31, 2006.

Benton, C. J., Mitchell, C.N., Isolating the multipath component in GNSS signal-to-noise data and locating reflecting objects, Radio Sci., 46, art. RS6002, doi:10.1029/2011RS004767, 2011.

Bilich, A., Larson, K.M., Axelrad, P., Modeling GPS phase multipath with SNR: Case study from Salar de Uyuni, Bolivia, J. Geophys. Res., 113, art. B04401, doi 10.1029/2007JB005194, 2008.

Bindoff, N.L., Willebrand, J., Artale, V., et al., Observations: Oceanic climate change and sea level, in: Solomon, S., Qin, D., Manning, M., et al. (Eds.), Climate Change 2007: The Physical Science Basis. Contribution of Working Group I to the Fourth Assessment Report of the Intergovernmental Panel on Climate Change. Cambridge University Press, Cambridge, United Kingdom and New York, NY, USA, 2007.

Cardellach, E., Ao, C.O., de la Torre Juárez, M., et al., Carrier phase delay altimetry with GPSreflection/occultation interferometry from low Earth orbiters, Geophys. Res. Lett., 31, art. L10402, doi:10.1029/2004GL019775, 2004.

Chambers, D., Ries, J.C., Shum, C.K., et al., On the use of tide gauges to determine altimeter drift, J. Geophys. Res., 103(C6), 12885-12890, 1998.

Dunne. S., Soulat, F., Caparrini, M., et al., OceanPal, A GPS-reflection coastal instrument to monitor tide and sea-state, Oceans-Europe, 2, 1351-1356, 2005.

Elósegui, P., Davis, J.L., Jaldehag, T.K., et al., Geodesy using the Global Positioning System: The effects of signal scattering on estimates of site position, J. Geophys. Res., 100(B6), 99219934, doi:10.1029/95JB00868, 1995.

Georgiadou, Y., A. Kleusberg, A., On carrier signal multipath effects in relative GPS positioning, Manusc. Geod., 13, 172-179, 1988.

Gurtner, W., RINEX: The Receiver-Independent Exchange Format, GPS World, 5(7), July 1994.

Hannah, B. M., Modelling and simulation of GPS multipath propagation, Ph.D. thesis, Queensland University of Technology, Brisbane, Australia, 2001.

IOC (Intergovernmental Oceanographic Commission) of UNESCO, Manual on sea level measurement and interpretation, IV: An update to 2006, IOC manuals and guides, JCOMM Technical Report No.31, WMO/TD. No.1339, 78 pp, Paris, 2006. 
Jaldehag, R.T.K., Johansson, J.M. Rönnäng, B.O., et al., Geodesy using the Swedish permanent GPS network: Effects of signal scattering on estimates of relative site positions, J. Geophys. Res., 101(B8), 17184-17860, doi:10.1029/96JB01183, 1996.

Joseph, A., What is the difference between SNR and C/NO? InsideGNSS, 5(8), 20-25, 2010.

Larson, K.M., Small, E.E. Gutmann, E., et al., Use of GPS receivers as a soil moisture network for water cycle studies, Geophys. Res. Lett., 35, art. L24405, doi:10.1029/2008GL036013, 2008.

Larson, K.M., Gutmann, E., Zavorotny, V., et al. Can we measure snow depth with GPS receivers? Geophys. Res. Lett., 36, art. L17502, doi:10.1029/2009GL039430, 2009.

Larson, K.M., Braun, J., Small, E.E., et al., GPS multipath and its relation to near-surface soil moisture content, IEEE J-STARS, 3, 91-99, doi:10.1109/JSTARS.2009.2033612, 2010.

Larson, K.M., Nievinski, F., GPS snow sensing: results from the EarthScope Plate Boundary Observatory, GPS Solut., doi 10.1007/s10291-012-0259-7, 2012.

Löfgren, J.S., Haas, R. Johansson, J.M., High-rate local sea level monitoring with a GNSS-based tide gauge, Proceedings of the 2010 IEEE IGRSS, 25-30 July, Honolulu, HI, USA, 36163619, 2010.

Löfgren, J.S., Haas, R., Johansson, J.M., Monitoring coastal sea level using reflected GNSS signals, Adv. Space Res., 47(2), 213-220, $2011 \mathrm{a}$.

Löfgren, J., Haas, R., Scherneck, H-G., et al., Three months of local sea level derived from reflected GNSS signals, Radio Sci., 46, art. RS0C05, doi:10.1029/2011RS004693, $2011 \mathrm{~b}$.

Lowe, S.T., LaBrecque, J.L., Zuffada, C., et al., First spaceborne observation of an Earthreflected GPS signal, Radio Sci., 37(1), art. 1007, doi:10.1029/2000RS002539, 2002.

Martin-Neira, M., A passive reflectometry and interferometry system (PARIS): Application to ocean altimetry, ESA J., 17, 331-355, 1993.

Martin-Neira, M., Caparrini, M., Font-Rossello, J., et al., The PARIS concept: an experimental demonstration of sea surface altimetry using reflected GPS signals, IEEE Trans. Geosci. Rem. Sens., 39(1), 142-150, 2001.

Mitchum, G. T., Comparison of Topex sea surface heights and tide gauge sea levels, J. Geophys. Res., 99(C12), 24541-24554, 1994.

Mitchum, G.T., An improved calibration of satellite altimetric heights using tide gauge sea levels with adjustment for land motion, Mar. Geod., 23, 145-166, 2000.

Park, K.-D., Elósegui, P., Davis, J.L., et al., Development of an antenna and multipath calibration system for Global Positioning System sites, Radio Sci., 39, art. RS5002, doi:10.1029/2003RS002999, 2004.

Press, F., Teukolsky, S., Vetterling, W., et al., Numerical Recipes in Fortran 90: The art of parallel scientific computing, 2nd Edition, Cambridge University Press, 1996.

Rius, A., Nogues-Correig, O., Ribo, S, et al. Altimetry with GNSS-R interferometry: first proof of concept experiment, GPS Sol., DOI: 10.1007/s10291-011-0225-9, in press.

Schöne, T., Schon, N., Thaller, D., IGS tide gauge benchmark monitoring pilot project (TIGA), Scientific benefits, J. Geod., 83(3-4), 249-261, 2009.

Soulat, F., Caparrini, M., Germain, O., et al., Sea state monitoring using coastal GNSS-R, Geophys. Res. Lett., 31, art. L21303, doi:10.1029/2004GL020680, 2004.

Treuhaft, R., Lowe, S., Zuffada, C., et al., 2-cm GPS altimetry over Crater Lake, Geophys. Res. Lett., 22(23), 4343-4346, 2001. 

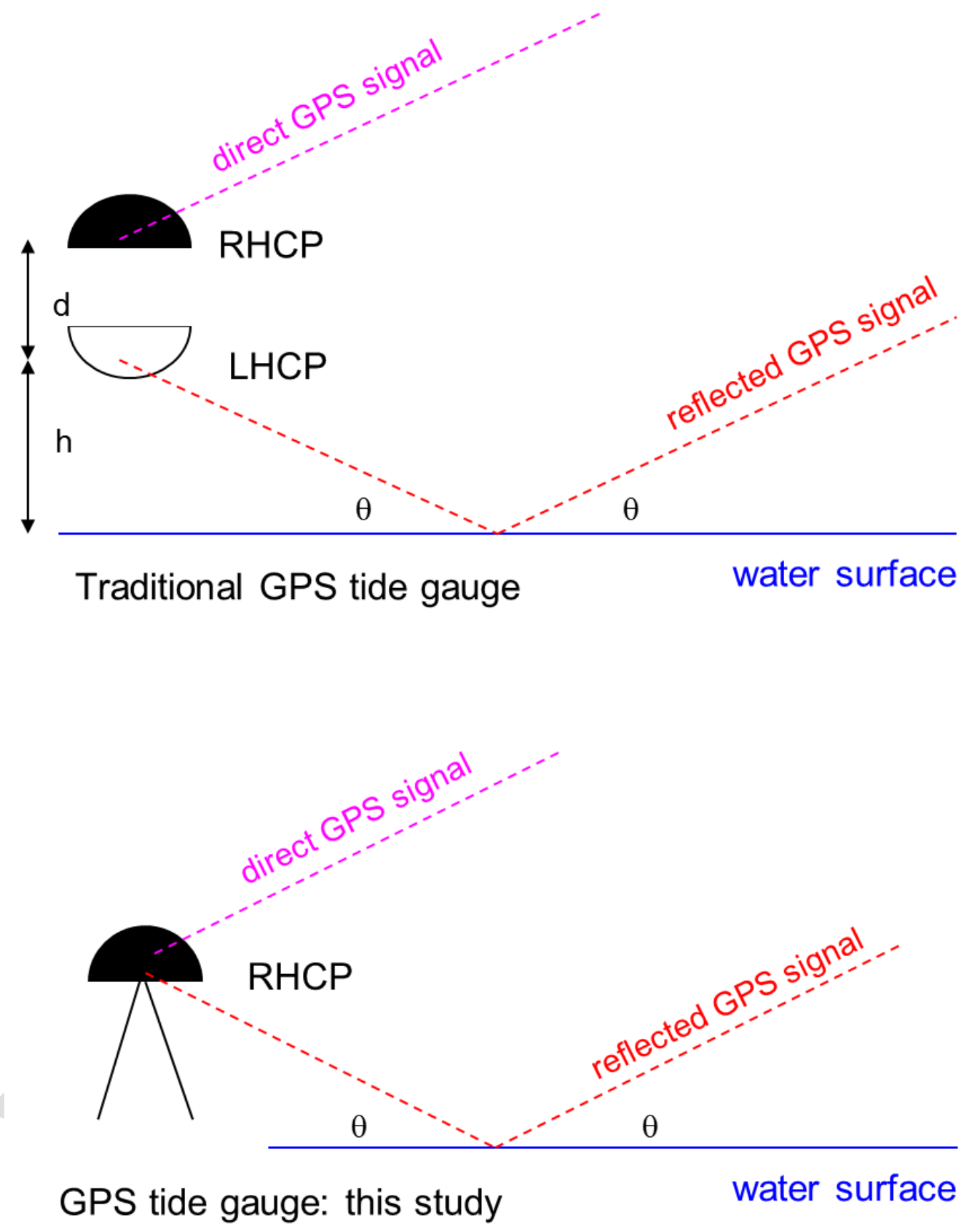

Figure 1. Top: a traditional GPS tide gauge with two GPS antennae and two receivers. The geodetic-quality antennae are mounted over the sea surface. A Right-Handed Circularly Polarized (RHCP) antenna is pointed to zenith and receives the direct signals. A Left-Handed Circularly Polarized (LHCP) antenna is pointed to nadir and receives the signals that are reflected off the sea surface. Bottom: the GPS tide gauge system used in this study has one RHCP antenna and one receiver. The antenna is of geodetic-quality and pointed in the zenith direction. The direct signals are received from above and the reflected signals (multipath) from the antenna backside. 


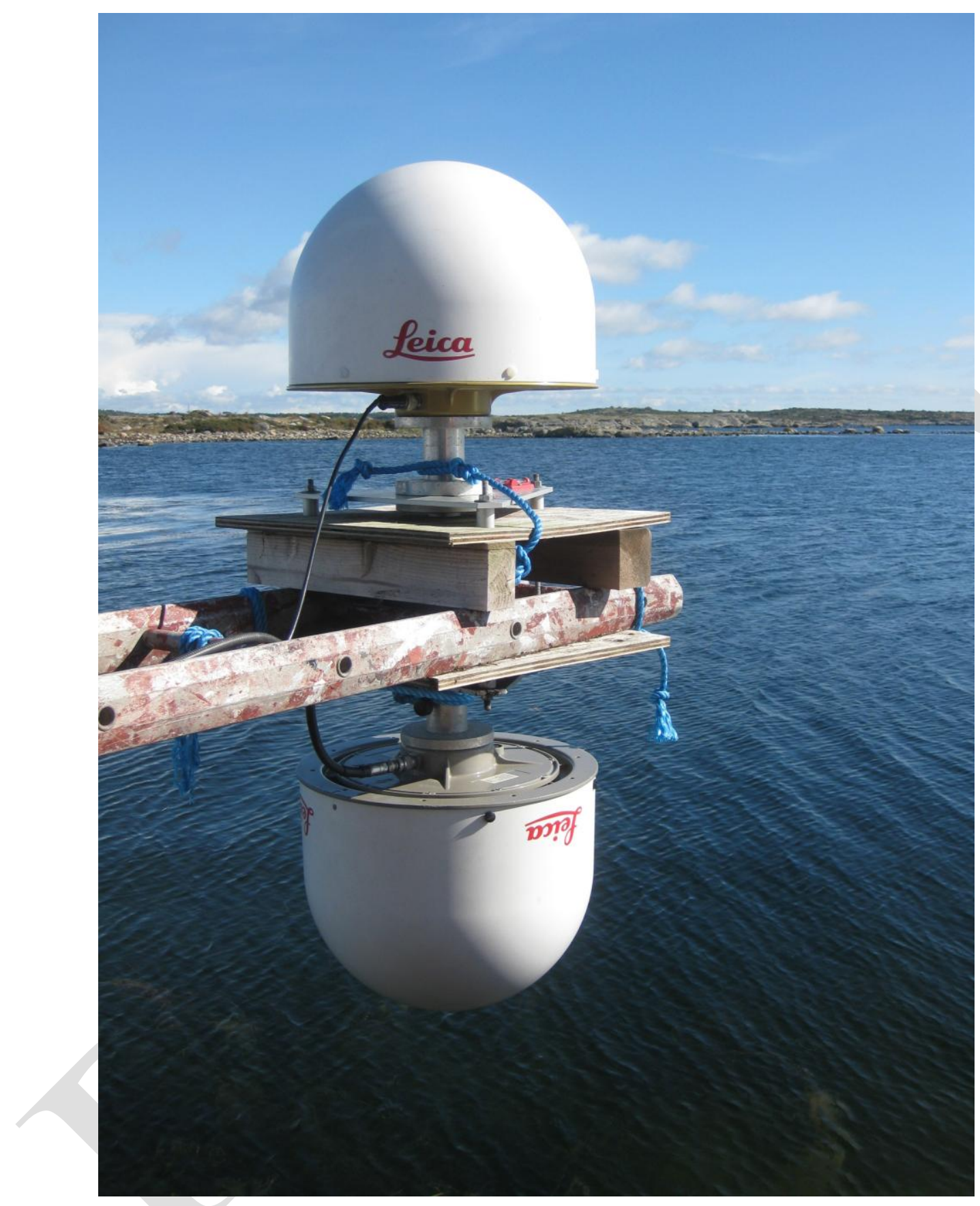

Figure 2. Photograph of the GPS tide gauge at the Onsala Space Observatory at the west coast of Sweden. Only the data received with the zenith-pointing antenna are used in this study. 

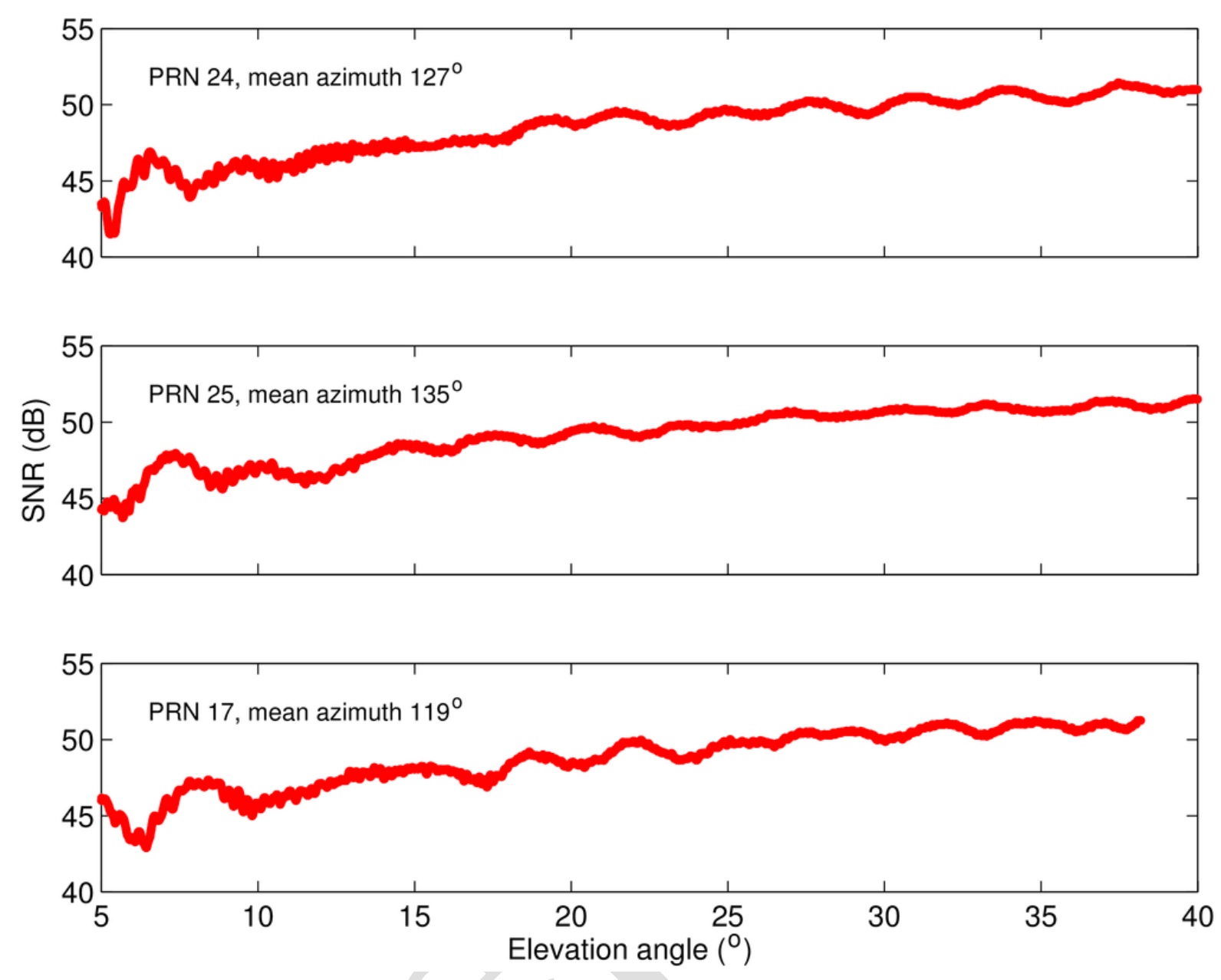

Figure 3. Signal-to-noise ratio measurements on the L1 frequency for three satellites, with Pseudo-Random Noise (PRN) numbers 24, 25, and 17, that rise/set over the ocean at Onsala, Sweden. Mean azimuth angles of the satellite tracks and PRN numbers are given in the upper left hand corner. Data are all from the zenith-directed right-handed circularly polarized geodeticquality antenna. 

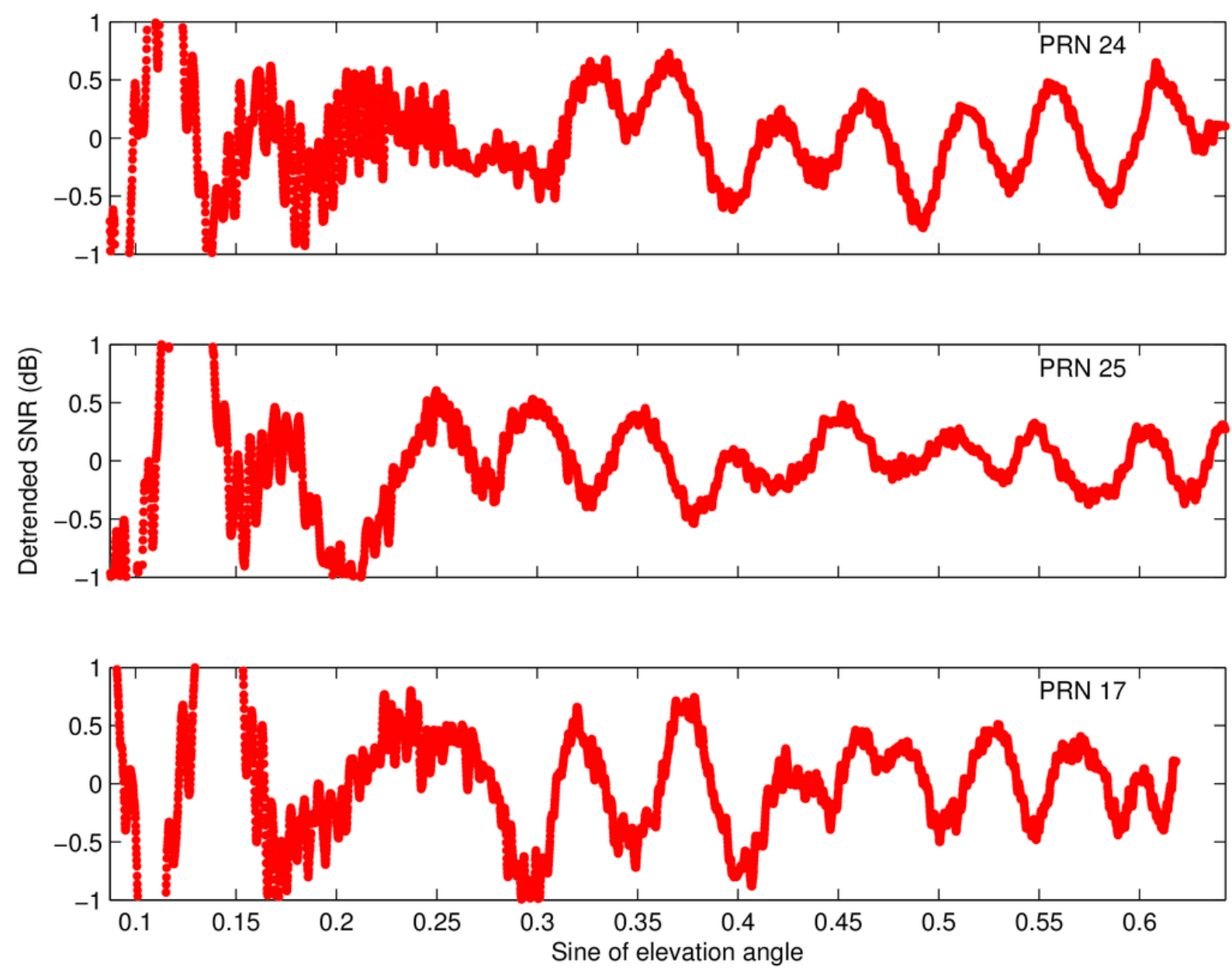

Figure 4. Detrended Signal-to-Noise Ratio measurements from Figure 4 where a $2^{\text {nd }}$ order polynomial is removed for each satellite. The values are shown as a function of sine of elevation angle and represent the interference between the direct and multipath signals. The oscillation frequency is related to the antenna height over the sea surface, see Equation 2. 


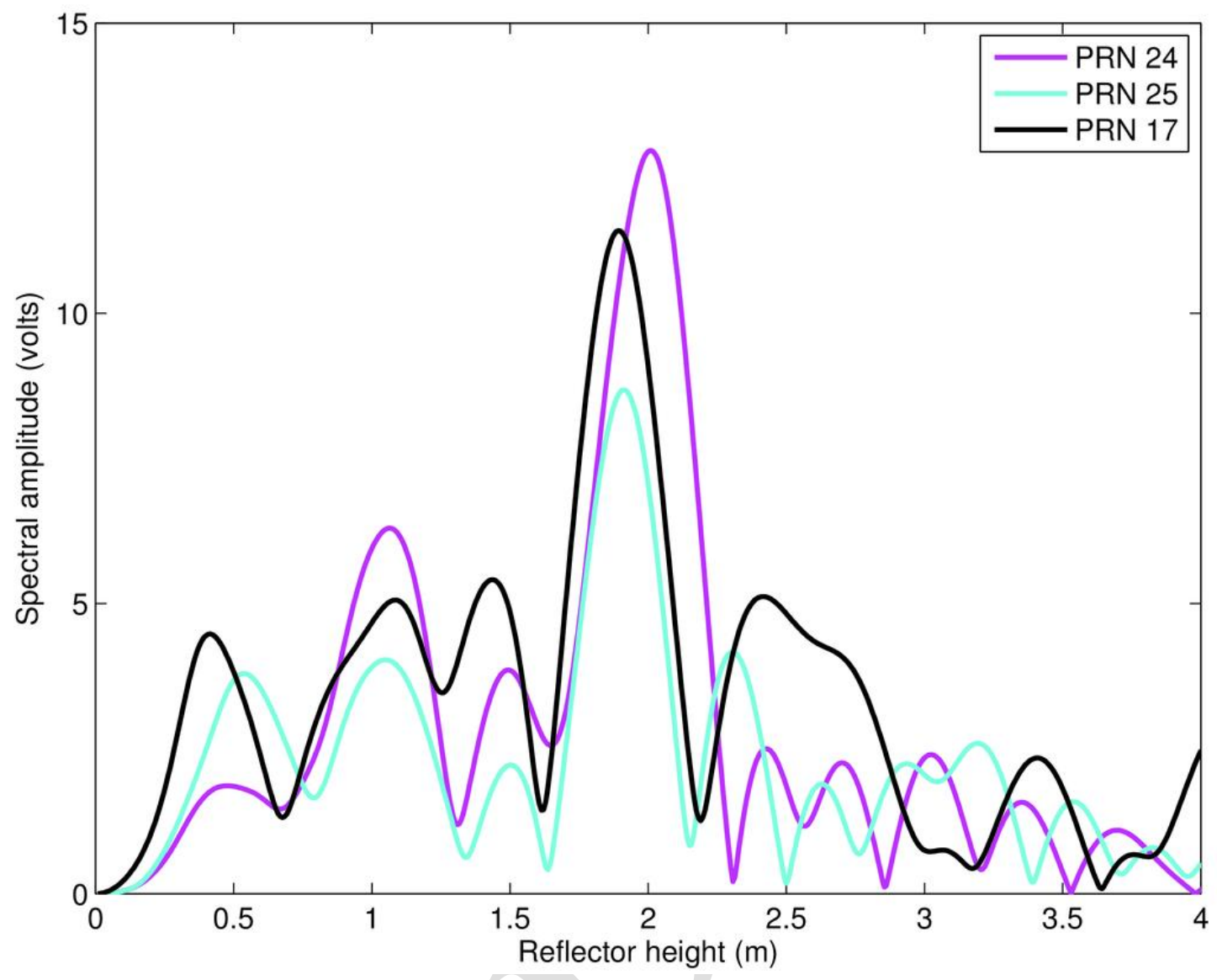

Figure 5. Lomb Scargle Periodograms (LSP) of the data shown in Figure 4. Only data for elevation angles between $18^{\circ}$ and $40^{\circ}$ were used. The peaks of the LSP determine the reflector heights that are used to estimate sea level. 


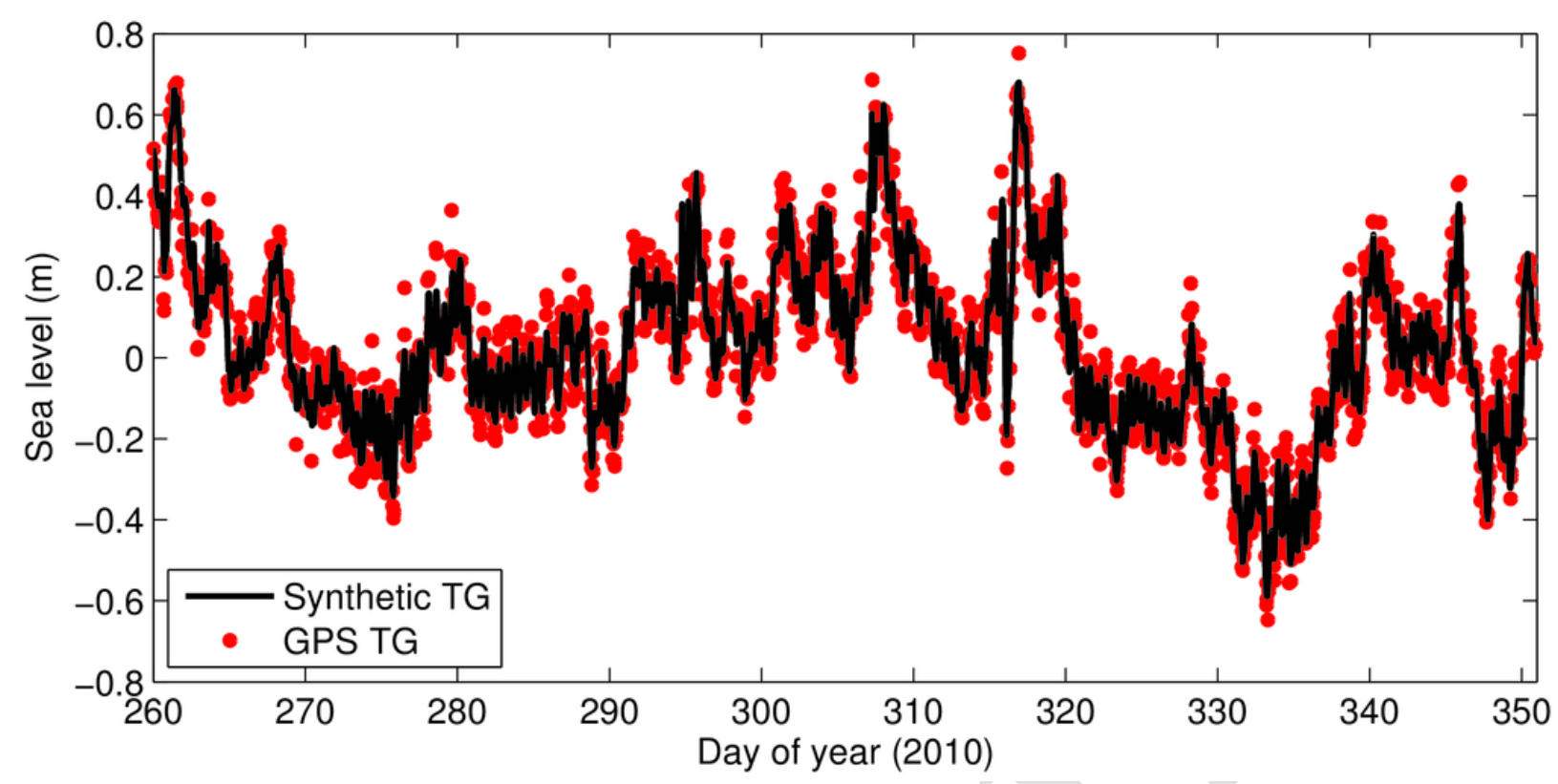

Figure 6. Sea level from a synthetic tide gauge at Onsala (black line), calculated from a weighted mean of tide gauge observations at Ringhals and Gothenburg, and estimated sea level measurements from the Onsala GPS tide gauge (red dots). 


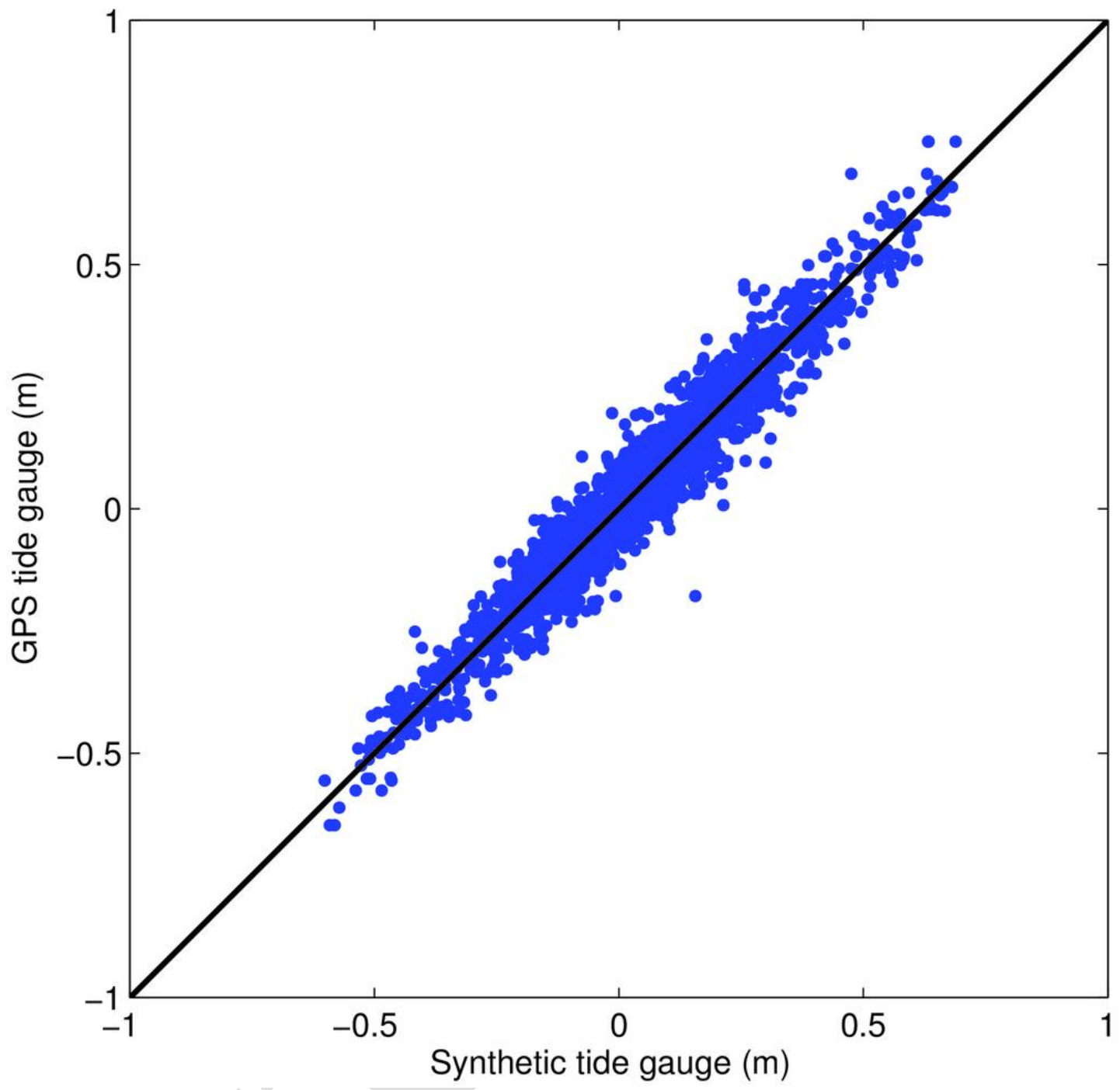

Figure 7. A scatter plot between the synthetic tide gauge sea level at Onsala, calculated from a weighted mean of Ringhals and Gothenburg tide gauge records, and the GPS tide gauge measurements at Onsala. The correlation coefficient is 0.97 . 


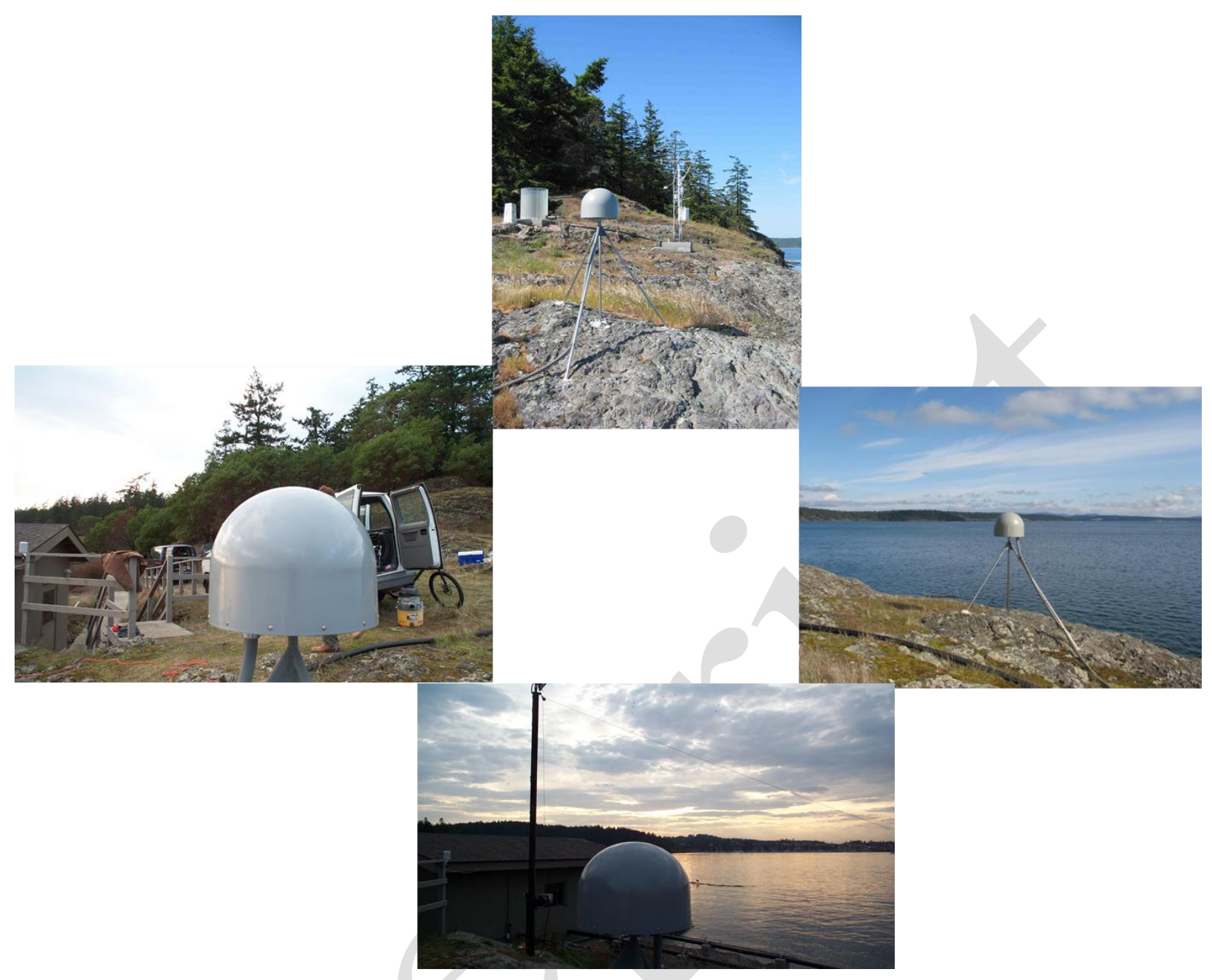

Figure 8. Photographs of the Friday Harbor GPS site, provided by UNAVCO. The top, right, bottom, left photographs correspond to the views towards north, east, south, west, respectively (the photograph to the south has been reversed). 


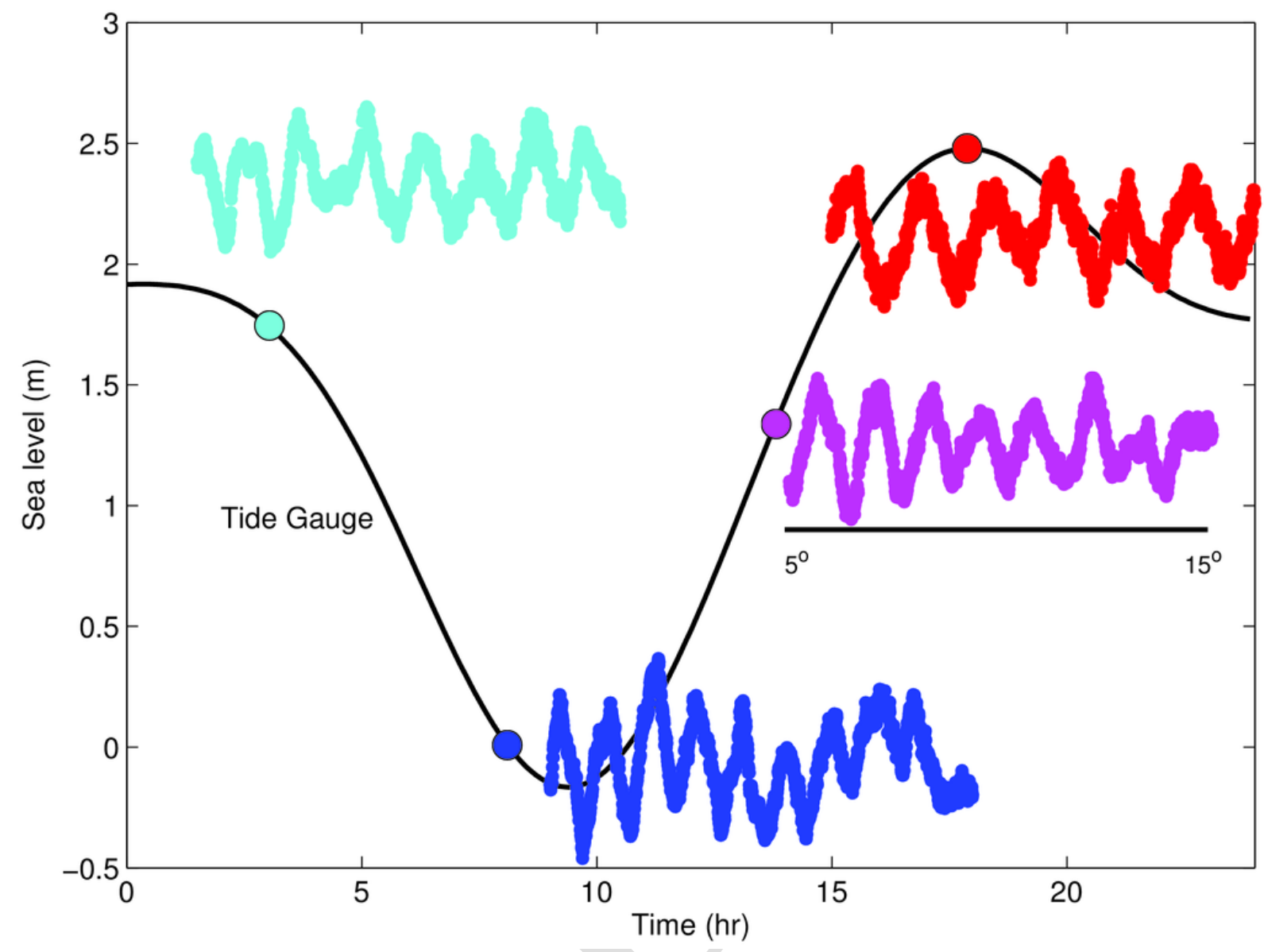

Figure 9. Signal-to-Noise Ratio (SNR) variations for GPS satellites with Pseudo-Random Noise (PRN) numbers 17 (red), 7 (magenta), and 31 (rising is cyan and setting is green) for elevation angles of $5^{\circ}-15^{\circ}$ from the Friday Harbor GPS site. Before plotting, the effects of the direct signal were removed from the SNR data with a 2nd order polynomial. The SNR data are superimposed on the NOAA tide gauge record for Friday Harbor at the time the satellite was rising/setting over the harbor (shown by the circles). The x-axis for each SNR time series has been exaggerated to make it easier to see the multipath oscillations in the data; each satellite track actually extends only $\sim 25$ minutes. 


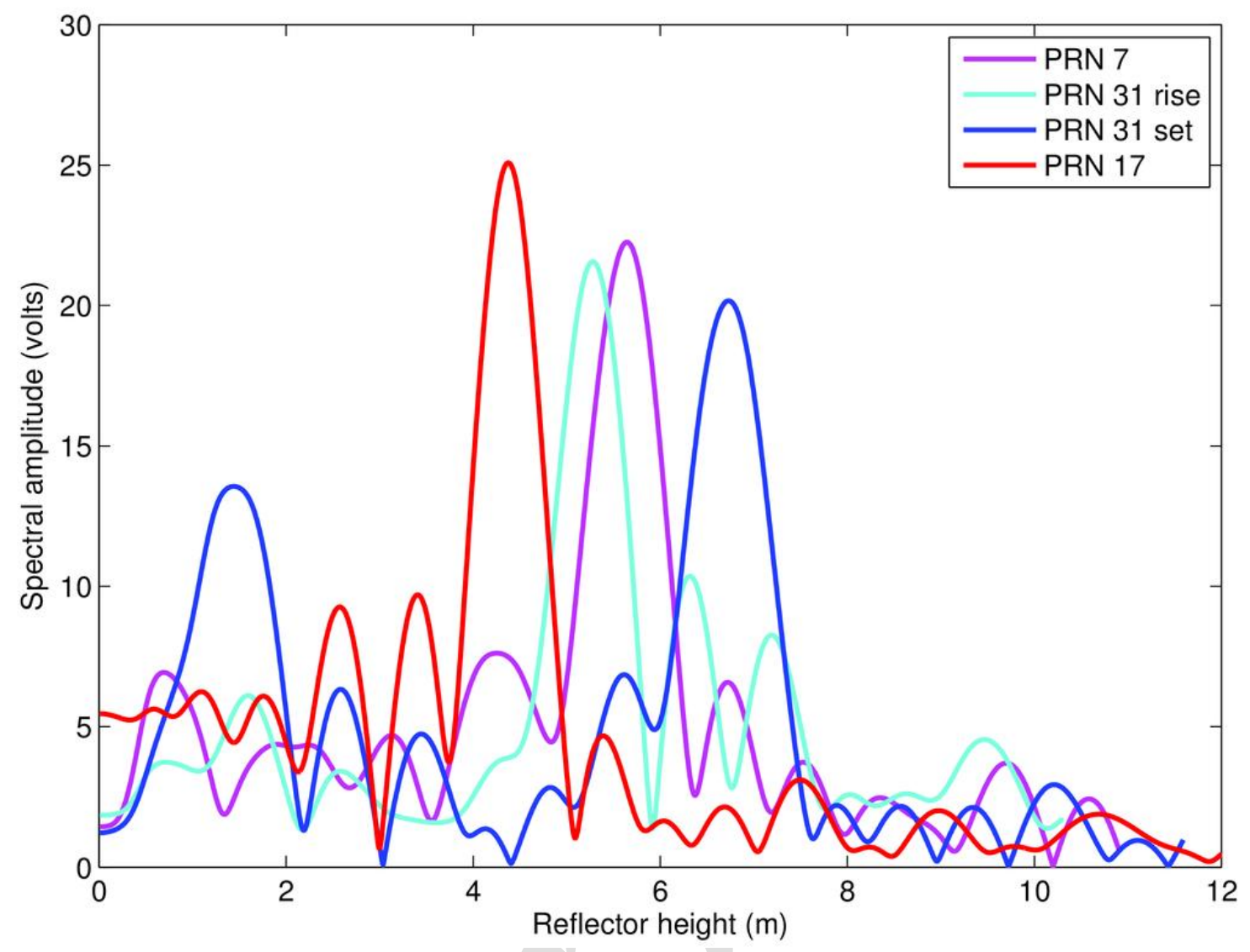

Figure 10. Lomb Scargle Periodograms for the data shown in Figure 9. Increases in reflector height correspond to a decrease in sea level. 


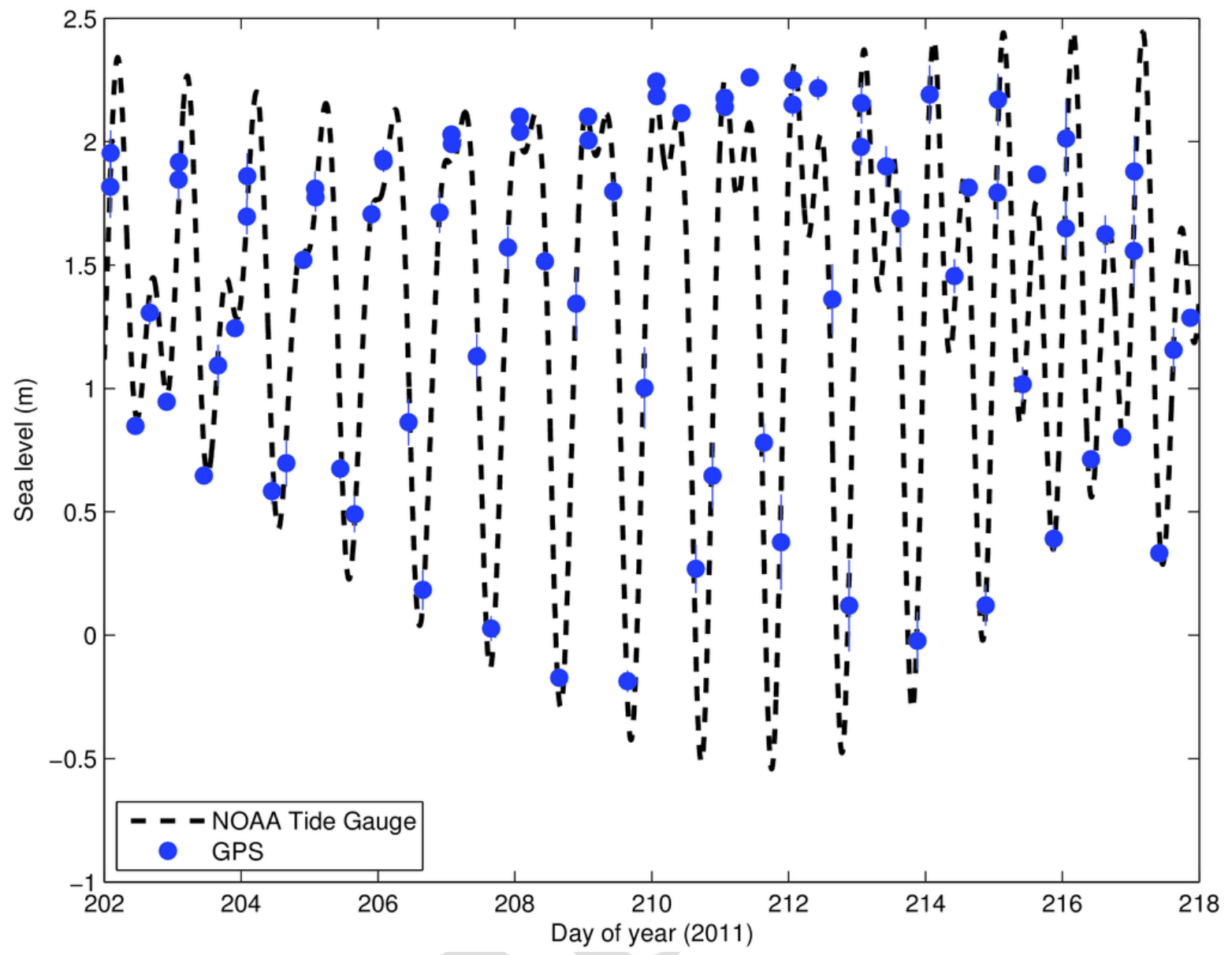

Figure 11. The Friday Harbor sea level records estimated from GPS (blue dots, 5 per day) and measured by the NOAA (black dashed line) tide gauge. 


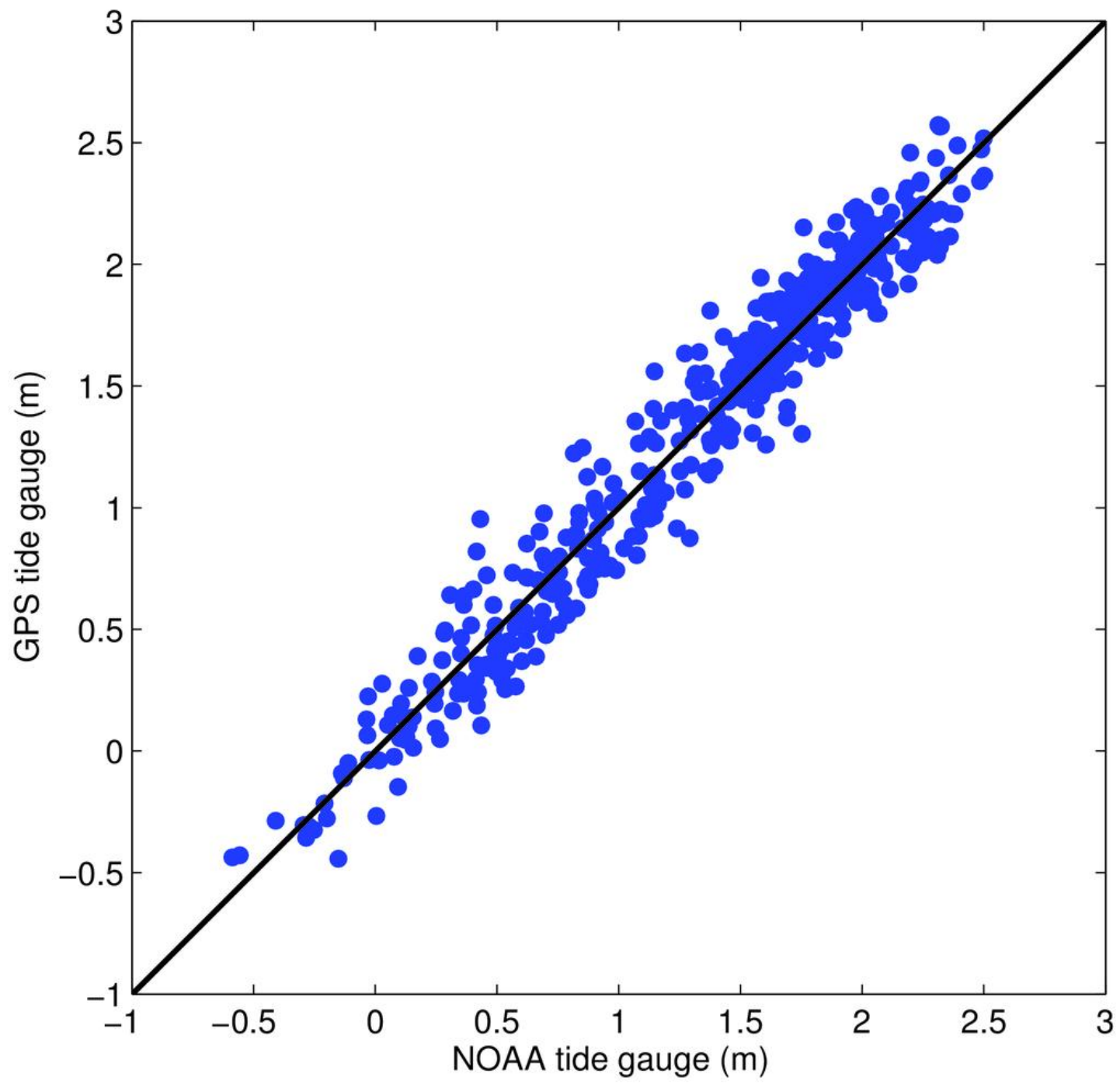

Figure 12. A scatter plot between the sea level results from the NOAA and the GPS tide gauge at Friday Harbor. The correlation coefficient is 0.98 . 

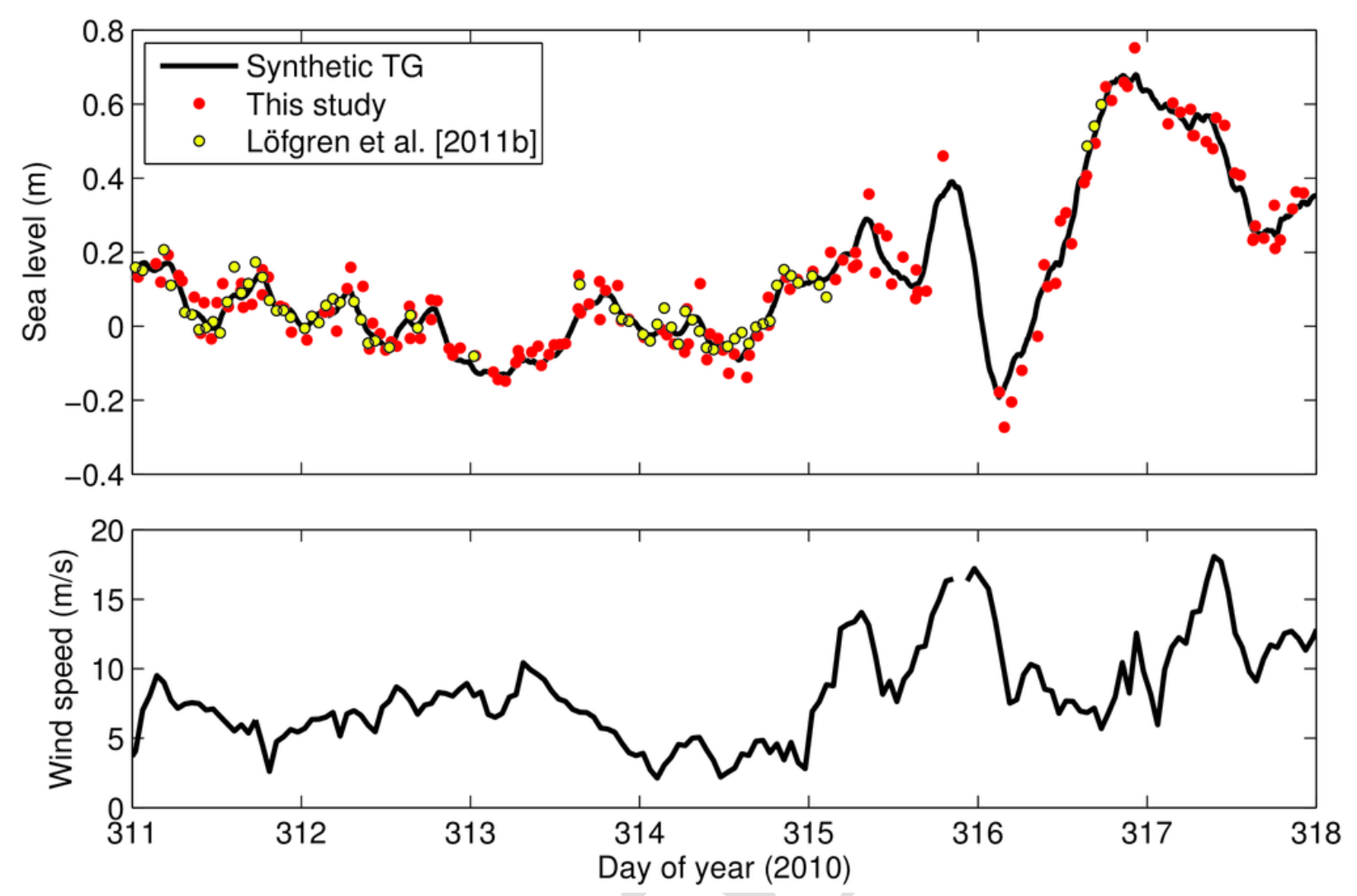

Figure 13. Top: the synthetic tide gauge record for Onsala (black line), the GPS tide gauge results presented in this study (red dots), and the GPS tide gauge results by Löfgren et al. (2011b) (yellow dots). Bottom: recorded wind speeds at Onsala Space Observatory. 